\title{
EFFECT OF HEATING RATE ON THE CRACK FORMATION DURING BAKING IN CARBON ANODES USED IN ALUMINUM INDUSTRY
}

\author{
Salah Amrani ${ }^{1}$, Duygu Kocaefe ${ }^{1}$, Yasar Kocaefe ${ }^{1}$, Brigitte Morais ${ }^{2}$, Gerry Blaney ${ }^{2}$ \\ ${ }^{1}$ UQAC/Aluminerie Alouette Research Chair on Carbon, University of Québec at Chicoutimi, \\ 555 Boulevard de l'Université, Chicoutimi, Québec, Canada G7H 2B1 \\ ${ }^{2}$ Aluminerie Alouette Inc., 400, Chemin de la Pointe-Noire, Sept-Îles, Québec, Canada G4R 5M9
}

Keywords: Carbon anodes, cracking, heating rate, baking, investigation techniques.

\begin{abstract}
The quality of carbon anodes used in aluminum industry depends on the raw material properties and the manufacturing process parameters. It is one of the key factors directly related to the aluminum production cost. The degradation in anode quality such as crack formation increases the energy consumption, the environmental emissions, and the smelter's overall operating cost.

The objective of this work is to investigate the formation of cracks in several industrial green anode samples during baking at different heating rates and to determine the influence of this baking parameter on the crack formation. The samples were characterized before and after baking by measuring a number of physical properties (electrical resistivity, density, etc.) which define the final quality of the anode samples. Also, techniques based on ultra-sound and scanning electron microscopy were used to determine the extent of cracking after baking.
\end{abstract}

\section{Introduction}

The identification of defects at intermediate stages of production, if possible, is important to reduce cost by eliminating the defective material and preventing its further processing. The defects are not always easy to detect during production; sometimes the defects in the final product may even go undetected.

Generally, it is better to start with the identification of the origin of anomalies to select appropriate methods for their detection. The existence of cracking, a physical phenomenon that occurs in materials, poses major problems and causes loss of productivity for many industries. These include aeronautic applications, nuclear installations, various concrete structures as well as carbon anodes used for the production of aluminum. The development of a crack in an anode, either microscopic or macroscopic and in different forms [1-3], is considered a discontinuity in this material. This causes an increase in electrical resistivity, and consequently an increase in energy consumption accompanied by considerable release of greenhouse gas emissions. Several factors cause the formation of this defect in dense carbon anodes and spread over several stages of the anode manufacturing process: raw material properties [4-6], green anode production process [7, 8], and the baking phase [9].

At the industrial level, the identification of the presence of cracks in an anode is carried out after the green anode production and baking phases; and the procedure involves an investigation by an automatic unit, visual inspection or a combination of both. The anodes are inspected based on a standard procedure established by the plant, and the defective ones that do not meet the standards are rejected. This increases the aluminum production cost.

The identification of cracks in carbon anode samples in a laboratory can be achieved by using several techniques. The determination of physical and mechanical properties [10-12] is necessary to determine the final quality of the anode produced. Different methods are available to study the structure and the morphology of materials at the microscopic level [13] using optical microscope, SEM, etc. or to carry out investigations at the macroscopic level using techniques such as tomography $[14,15]$ and ultrasound [16-21].

The evaluation of cracks involves the determination of the dimensions (length and width) as well as the percentage of cracked areas. Anode quality depends on raw material properties and all process parameters during its manufacturing. Baking is the last step where the final anode properties are fixed. Thus, the performance of the baking process is important for the final anode quality, and low rates of heating are recommended to avoid cracking [22-28]. The control of the baking process is essential to reduce the cost of operation on one side and to minimize the formation of cracks on the other. The anode baking is carried out in large furnaces where several parameters play an important role on anode properties, and the anode temperature reaches a maximum value which usually varies between $1050-1200^{\circ} \mathrm{C}$ depending on the smelter.

The analysis of anode samples using above characterization techniques can give an insight into the cracking problem. The objective of this work is to determine the effect of heating rate during baking on the cracking of anodes. The work was carried out on samples from industrial anodes that were vibro-compacted at about $170^{\circ} \mathrm{C}$. The green anodes contained around 13-15\% pitch, and the baking was done in a laboratory-scale furnace. The work also involved testing the application of various techniques for crack investigation. The techniques used were the scanning electron microscopy (SEM) to look at the samples at the microscopic scale and the ultra-sound at the macroscopic scale.

\section{Methodology}

Three series of cylindrical samples of $50 \mathrm{~mm}$ in diameter and $130 \mathrm{~mm}$ in length were baked in a furnace at the University of Québec at Chicoutimi (UQAC). Baking was done at different heating rates since the aim was to determine the influence of this parameter on the formation of cracks in industrial anodes represented by these samples. Heating rates of $11^{\circ} \mathrm{C} / \mathrm{h}, 20^{\circ} \mathrm{C} / \mathrm{h}$, and $60^{\circ} \mathrm{C} / \mathrm{h}$ were used. The first two cover mostly various stages of anode baking whereas the last one was to test an extreme 
condition which is not likely to be seen in a normal furnace operation. Also, the anodes were maintained at the maximum temperature of $1050^{\circ} \mathrm{C}$ for a certain period of time, called the soaking time. The three series of experiments were performed in a Pyradia furnace.

In the laboratory baking furnace, conditions similar to those of the industrial furnace were used, and packing coke was filled around anode samples. Inert gas is passed through the system. The evolution of the temperature in the furnace was programmed to provide the desired heating rate. Data acquisition system recorded the temperatures measured by a thermocouple placed in contact with the upper surface of the sample. After the completion of the baking cycle, the furnace was turned off, and the samples were allowed to cool down to room temperature in inert gas atmosphere in the furnace. After cooling, the samples were taken out; and a visual inspection followed by a series of analyses for the determination of physical properties as well as structural characterization was carried out. Table I gives the set times for different periods during baking as well as the times obtained experimentally. The temperature profiles during the baking experiments for different heating rates are shown in Figure 1.

Table I. Set and experimental times for heating and soaking periods during baking

\begin{tabular}{|l|l|c|c|c|}
\cline { 3 - 5 } \multicolumn{2}{c|}{} & $\begin{array}{c}\text { Series I } \\
11^{\circ} \mathrm{C} / \mathrm{h}\end{array}$ & $\begin{array}{c}\text { Series II } \\
20^{\circ} \mathrm{C} / \mathrm{h}\end{array}$ & $\begin{array}{c}\text { Series III } \\
60^{\circ} \mathrm{C} / \mathrm{h}\end{array}$ \\
\hline \multirow{3}{*}{$\begin{array}{l}\text { Experimental } \\
\text { time (h) }\end{array}$} & Heating & 97.5 & 54.7 & 22.8 \\
\cline { 2 - 5 } & Soaking & 8.2 & 8.8 & 8.6 \\
\cline { 2 - 5 } & Total & 106.3 & 63.5 & 31.4 \\
\hline \multirow{3}{*}{ Set time (h) } & Heating & 95.9 & 52.7 & 17.8 \\
\cline { 2 - 6 } & Soaking & 12 & 12 & 12 \\
\cline { 2 - 6 } & Total & 107.9 & 64.7 & 29.8 \\
\hline
\end{tabular}

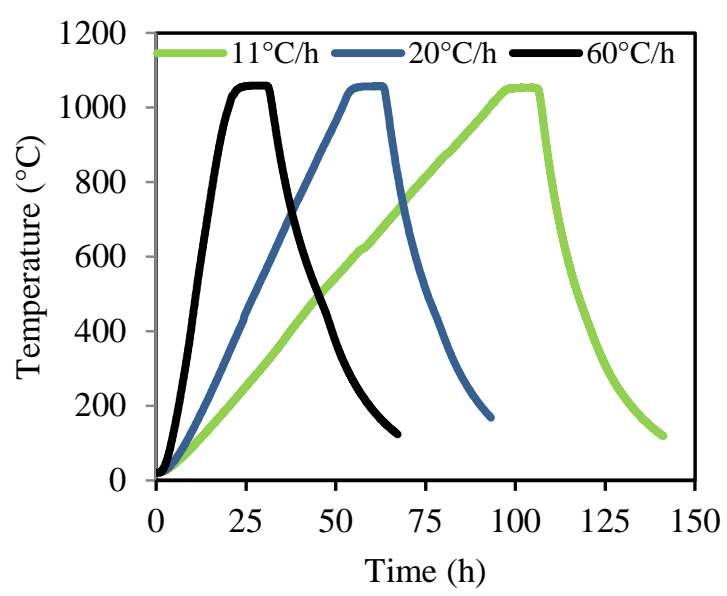

Figure 1. Temperature profiles obtained at different heating rates.

\section{Measurement of physical properties}

Different physical properties (bulk density and electrical resistivity) were determined using ASTM standards [29, 30]. The apparent density was measured using ASTM D5502-00 (2005). This is a standardized test to determine the bulk density by physical measurements on a cylindrical sample for anodes and cathodes in aluminum industry. The electrical resistivity was measured according to ASTM D6120-97 (2007). This test is used to determine the electrical resistance of a cylindrical sample of anodes and cathodes. Knowledge of the actual density and the apparent density of an anode allows the calculation of its total porosity [Erreur! Signet non défini.].

\section{Analysis by scanning electron microscopy (SEM)}

The scanning electron microscopy was used for the investigation of cracks formed in baked samples. This method focuses on the form and mechanism of crack growth by examining the structural changes in anode during baking.

\section{Analysis by ultra-sound}

The ultra-sound technique was used to locate and identify the existence of cracks formed during baking. The principle of the technique involves injecting repetitive series of ultrasonic pulses into the material using a potentiometric transducer. Each pulse produces stress waves which are similar to the acoustic emission events induced by the propagation of micro-cracks in the material under stress. It has the advantage of providing information on the location, size, and distribution of cracks in the samples analyzed and consequently the quality of the entire anode sample.

\section{Analysis by visual inspection}

The surface of the sample was visually inspected before putting them in the furnace. At the end of baking, the samples were inspected again visually. The results of the two states of the sample surface were compared to determine the effect of baking on the formation of cracks on the surface.

\section{Results and discussion}

\section{Characterization by visual inspection}

Figure 2 shows a crack formed on the surface of a sample (encircled by a broken red line) found by visual inspection. All of the three series of samples baked at different heating rates were inspected visually. Small cracks were found on the surfaces of all samples. However, these are surface cracks and are not representative of the matrix of the samples.

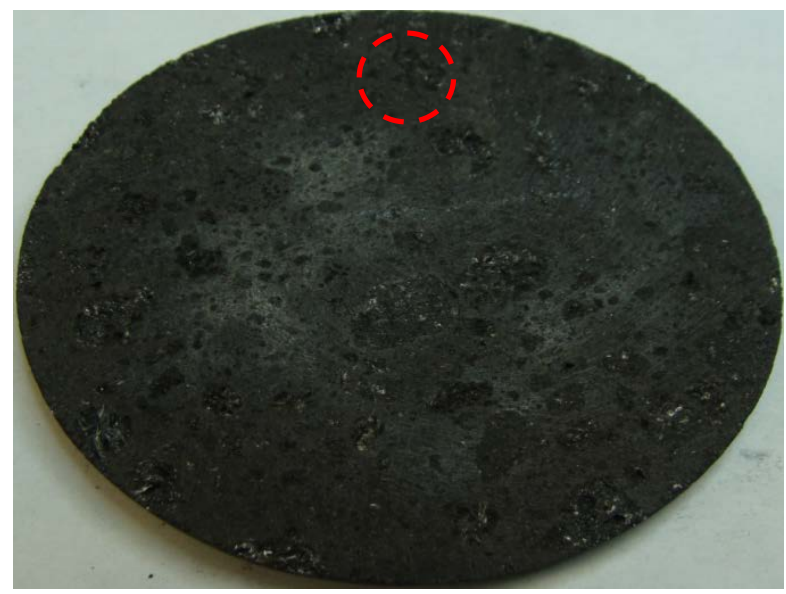

Figure 2. A surface crack formed during baking (visual inspection). 
The investigation of the crack formation by visual inspection is not sufficient for a complete description of the matrix of the sample. For this reason, other techniques were used to determine the presence of internal cracks.

\section{Characterization by the determination of the physical parameters}

The investigation of defects in baked samples can be carried out by determining the change in the physical properties due to baking. In this work, apparent density and electrical resistivity were determined for each sample before and after baking. The measured apparent density was used to calculate the porosity of the samples. The specific electrical resistivity of green anodes can differ significantly due to the difference in the quantity of cracks/pores or pitch content. It should be noted that the presence of cracks always increases the electrical resistivity of both baked and unbaked anodes. The relationship between anode pitch content and the variation in electrical resistivity due to baking is somewhat complex. If the amount of pitch is high in the green anode, the electrical resistivity will be high. The resistivity will decrease after baking due to pitch coking as the structure of carbonized pitch is more conductive than pitch itself. However, volatiles released during baking can increase the internal pressure in the anode and create cracks which increase electrical resistivity.

Table II presents cases to illustrate these phenomena. Case 1 shows that for similar values of green anode electrical resistivities, the baked anode resistivity increases with increasing heating rate. This can be explained in terms of more rapid devolatilization at the higher heating rate that generates more cracks or/and results in a more porous structure. Case 2 shows that, for the same heating rate, the electrical resistivities of baked anodes will usually be similar if the electrical resistivities of the corresponding green anodes are similar. Case 3 shows two green anode samples with considerably different electrical resistivities. At the same heating rate, higher green anode resistivity results in higher baked anode resistivity; however, the differences in the resistivities of the baked anodes are not as significant as those of the green anodes. This may be attributed to the presence of a higher amount of pitch in the green anode sample with high electrical resistivity (the pitch content is about $40-50 \%$ greater than the other one). Upon the coking of pitch, this sample becomes nearly as conductive as the other one.

Table II. Comparison of electrical resistivities before and after baking for different cases.

\begin{tabular}{|c|c|c|c|}
\hline \multirow{2}{*}{ Case } & \multirow{2}{*}{$\begin{array}{c}\text { Heating rate } \\
\left({ }^{\circ} \mathrm{C} / \mathrm{h}\right)\end{array}$} & \multicolumn{2}{|c|}{ Specific electrical resistivity $(\mu \Omega \cdot \mathrm{m})$} \\
\cline { 3 - 4 } & 11 & $1600-1800$ & $53-56$ \\
\hline \multirow{2}{*}{1} & 20 & $1600-1800$ & $54-59$ \\
\cline { 2 - 4 } & 11 & $1600-1800$ & $53-56$ \\
\hline \multirow{2}{*}{2} & 11 & $1600-1800$ & $53-56$ \\
\cline { 2 - 4 } & 60 & $3080-3230$ & $53-56$ \\
\hline \multirow{2}{*}{3} & 60 & $4550-4690$ & $55-61$ \\
\hline
\end{tabular}

The values of the electrical resistivities of baked samples are much lower than those of the green samples (1600-4690 vs. 53-61 $\mu \Omega \cdot \mathrm{m})$. The reduction in apparent density due to baking is around
$5 \%$ as a result of the combined effect of the weight loss (devolatilization) and the shrinkage of the baked sample.

The values in Figures 3 and 4 are given on a relative basis: the value of the physical property for a green or baked sample was divided by the average of all measured values of the green or baked samples, respectively, for that property. Figure 3 shows the change in electrical resistivity due to baking for three samples at $60^{\circ} \mathrm{C} / \mathrm{h}$. These three samples had different electrical resistivities before baking. The electrical resistivities decreased in a similar manner during baking since a linear relationship was obtained between the values for green vs. baked samples. The data can be correlated as a line with a correlation coefficient $\left(\mathrm{R}^{2}\right.$ value) of 0.9959. This means that the same changes occurred during baking for all three samples baked at $60^{\circ} \mathrm{C} / \mathrm{h}$.

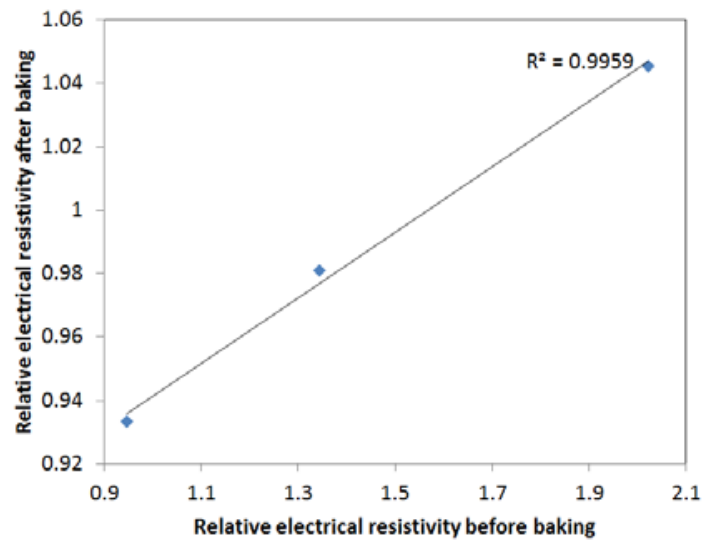

Figure 3. Change in the relative electrical resistivity due to baking for three samples baked at $60^{\circ} \mathrm{C} / \mathrm{h}$.

The total porosity was calculated by using the values of the real densities and measured apparent densities. The change in the relative total porosity due to baking for three samples at $60^{\circ} \mathrm{C} / \mathrm{h}$ is shown in Figure 4. The relative values were calculated as described before.

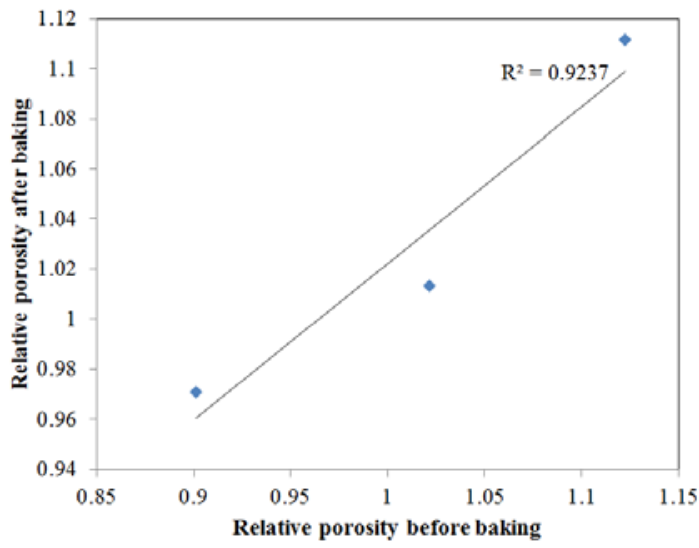

Figure 4. Change in relative total porosity due to baking for three samples baked to $60^{\circ} \mathrm{C} / \mathrm{h}$.

Porosity increases during baking due to the impact of devolatilization on the structure. The tendencies found for the total porosity are similar to those of the electrical resistivity. The 
data can be correlated as a line with an $\mathrm{R}^{2}$ value of 0.9237 (see Figure 4). Again, the linear relationship between the green and baked values shows that the changes are similar during baking for all samples. The relative values given in the figure are not indicative of the actual values.

\section{Characterization using SEM and ultra-sound techniques}

The characterization at the microscopic scale of the sample baked at $11^{\circ} \mathrm{C} / \mathrm{h}$ was carried out using the scanning electron microscopy (SEM). The SEM images are given in Figure 5. Figure 5(a) shows the middle of a crack formed during baking. The crack and the region around it have almost the same morphology. This indicates that part of the pitch is converted to carbon (coking), and the rest is volatilized by causing the formation of that crack. Figure 5(b) shows the end of the same crack given in 5(a). The structure of the crack and the surrounding area are not the same. Thus, this region was not completely covered by pitch (the dark color represents the voidage), and the cracking stopped here due to the absence of devolatilization.
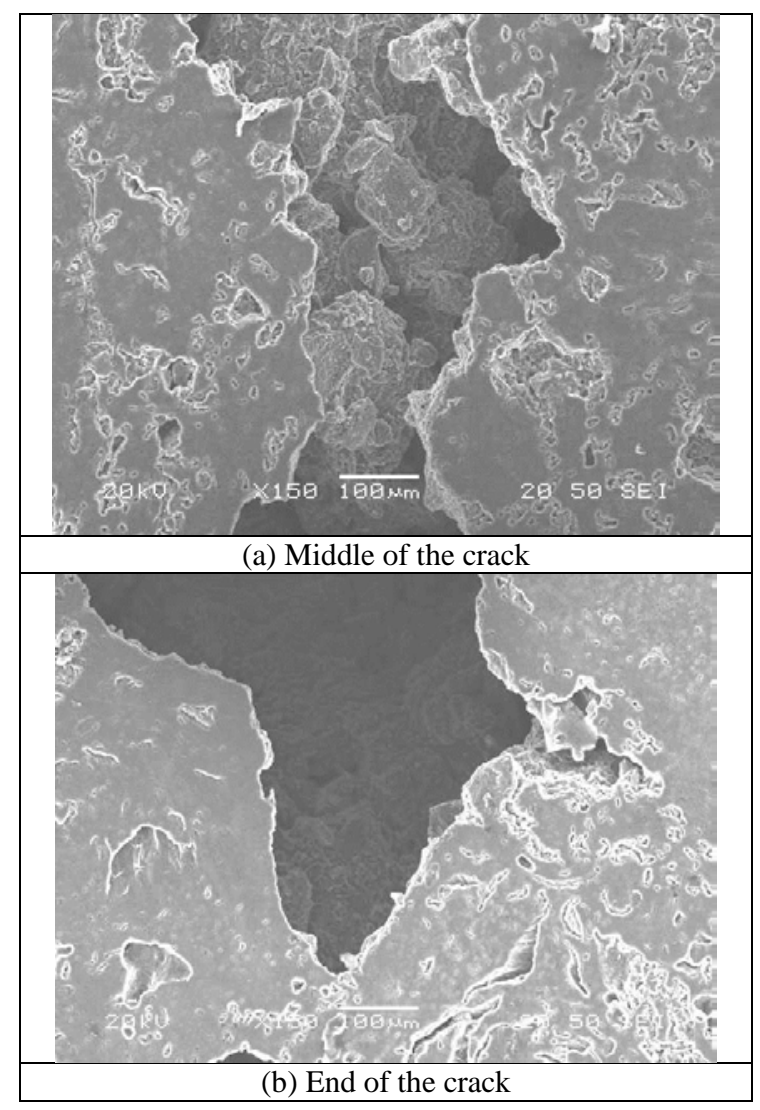

Figure 5. SEM images of a cracked area showing the mechanism of cracking in the sample baked at $11^{\circ} \mathrm{C} / \mathrm{h}$ : (a) the middle of the crack, (b) the end of the crack.

Two samples baked at $20^{\circ} \mathrm{C} / \mathrm{h}$ and $60^{\circ} \mathrm{C} / \mathrm{h}$ are characterized by the ultrasonic technique to investigate them at the macroscopic level. The results are given in Figure 6. The method can scan the entire sample and generate images representing different cross-sections. The colors indicate the status of each area of the sample: blue color for good quality (negligible amount of cracks), green and yellow are lower quality (presence of some cracks), and red and white for low quality (higher concentration of cracks). For the images obtained from the ultrasound analysis, a scale which indicates the position and the magnitude of the crack is given on the top of each image. Thus, two green regions (top and side) are reserved for the visual presentation of cracks and their depth.

Figure 6 (a) shows the state of the sample baked at $20^{\circ} \mathrm{C} / \mathrm{h}$ where the different regions of the sample are shown. A horizontal crack was spotted at $19 \mathrm{~mm}$ depth (measured from the top surface of the sample). Noises in the background are always detected by the system. They are not defects, but the reflection of sound from the surface of the sample. Figure 6 (b) shows the state of the sample baked at $60^{\circ} \mathrm{C} / \mathrm{h}$. In this case, the presence of two horizontal cracks located at depths of $63 \mathrm{~mm}$ and $67 \mathrm{~mm}$ can be clearly seen. This might indicate that there is more crack formation at higher heating rates. However, these tests have to be repeated with larger samples to derive more precise conclusions.

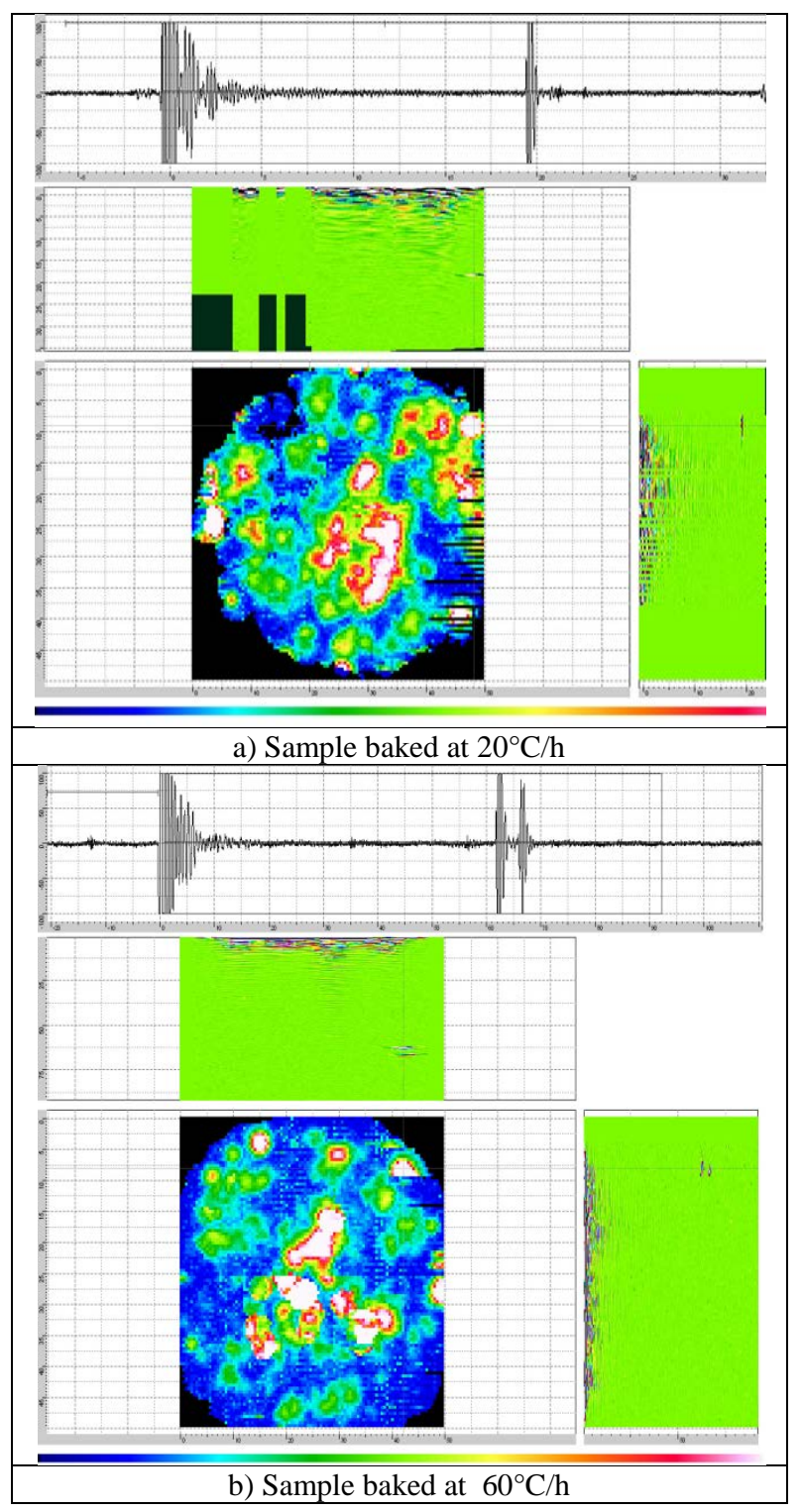

Figure 6. Images of baked anode samples generated by the ultrasound system. 


\section{Influence of impurities on the formation of cracks}

The preparation of anodes in industry goes through several stages. Impurities found in anodes usually come from the impurities present in raw materials. In addition, contamination can occur during the process such as from conveyors used to transport material, poorly cleaned mould, recycled material (improper butt cleaning), etc. The samples used during this study were prepared from an industrially produced green anode. Figure 7 shows an image of a section (13mm x $9 \mathrm{~mm})$ that was taken from a sample baked at $11^{\circ} \mathrm{C} / \mathrm{h}$. Inspection after baking indicates the presence of a white impurity (about $2 \mathrm{~mm}$ in diameter). This is most probably sodium coming from recycled butts. During baking, cracks may initiate from these impurities due to the expansion in their volume. This figure clearly shows that the white impurity shown in the red circle causes the formation of a crack on one side.

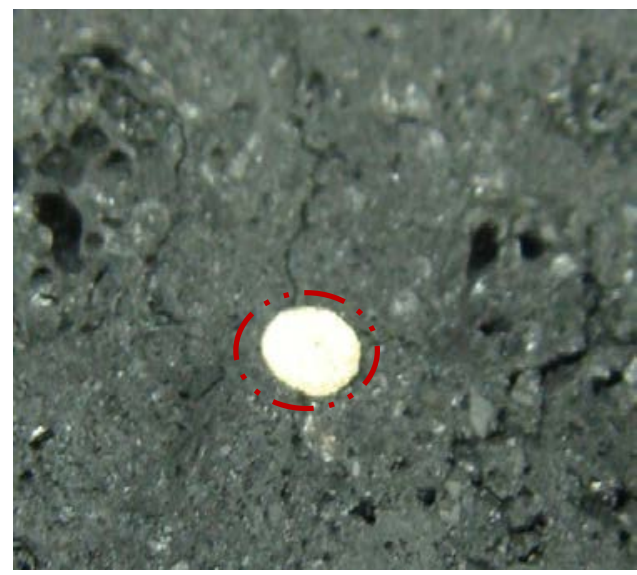

Figure 7. Crack caused by the presence of an impurity

\section{Conclusions}

Three series of cylindrical samples (130mm length x 50mm diameter) from an industrial anode were baked at different heating rates $\left(11^{\circ} \mathrm{C} / \mathrm{h}, 20^{\circ} \mathrm{C} / \mathrm{h}\right.$, and $\left.60^{\circ} \mathrm{C} / \mathrm{h}\right)$ in a furnace at UQAC. Following the baking, the samples were analyzed by different characterization methods. Their physical properties were determined before and after baking. The electrical resistivity values showed that, for similar initial conditions of green anodes, there is a greater tendency of crack formation after baking at higher heating rates. For similar heating rates, usually the resistivity of baked anodes is proportional to that of green anodes. Pitch content of green anodes has a significant effect on the electrical resistivity of baked anodes. The scanning electron microscopy analysis of the sample baked at $11^{\circ} \mathrm{C} / \mathrm{h}$ showed that the devolatilization and the presence of impurities can cause crack formation. The ultrasound analysis can indicate the magnitude and the position of the cracks. This analysis showed that there is relatively more crack formation at higher heating rate. Further testing with larger anode samples is needed to confirm these observations.

\section{Acknowledgements}

The technical and financial contributions of Aluminerie Alouette Inc. and the financial support from the Natural Sciences and Engineering Research Council of Canada (NSERC), the Economic Development Sept-Iles, the University of Quebec at
Chicoutimi (UQAC), and the Foundation of the University of Quebec at Chicoutimi (FUQAC) are greatly appreciated.

\section{References}

1. M. W. Meier, K. Cracking, cracking behaviour of anode. (R \& d. Carbone. Ltd. chapitre 4, 1996), 251-268.

2. M. W. Meier, K. Fischer, R. C. Perruchoud, thermal shok of anodes-a solved problem, Light Metals, (1994), anode for the aluminum industry ( $\mathrm{R} \& \mathrm{D}$ carbon, ltd, 4eme edition 2007), 321-323.

3. F. Keller, U. Mannweiler, R. C. Perruchoud, Anode performance, the link between coke properties and aluminum production cost, internal publication, (1994), anode for the aluminum industry, (R \& D carbon, ltd, 4eme edition 2007), 381-387.

4. L. Edwards, N. Backhouse, H. Darmstadt, M-J. Dion, Evolution of anode grade coke quality, Light Metals, (2012), 1207-1212.

5. M. Polovnikov, I.V. Cherskikh, E.A. Startsev, Effect of pitch quality on properties of baked anodes (The second international congress on nonferrous metals, Aluminum reduction technology, Part VI, 2010), 333-335.

6. K. Azari, H. Alamdari, G. Aryanpour , D. Picard, Mixing variables for prebaked anodes used in aluminum production, Powder Technology 235, (2013), 341-348.

7. M. Tkac, Porosity development in composite carbon materials during heat treatment (Ph.D thesis, Norwegian University of Science and Technology, 2007), 27-37.

8. O. E. Frosta, A. P. Ratvik, H. A. Øye, Properties and production conditions affecting crack formation and propagation in carbon anodes, Light Metals, (2012), 12931298.

9. A. Al Marzouqi, T. K. Sahu, S. A. Rabba, Baking Furnace Optimisation, Light Metals, (2008), 913-917.

10. W. K, Fischer, R. C. Perruchoud, Tests methods for the determination of prebaked anode properties, RDC internal publication (1992), Anode for the Aluminum Industry (R\&D Carbon Ltd, 4ème edition, 2007), 281-291.

11. W. K, Fischer, R. C. Perruchoud, Determination of prebaked anode properties, for Aluminum production, Journal of metals 39 (11), (1987), 43-45.

12. L. Eliassen, Characterization of the Mechanical Properties of Carbon Anode Materials (Master thesis, Norwegian University of Science and Technology, (2007).

13. S. Rørvik, L, P. Lossius, H. A. øye, Classification of pores in prebake anodes using automated optical microscopy, Light Metals, ( 2003), 531-534. 
14. D. Picard, H. Alamdari, D. Ziegler, P-O. St-Arnaud, M. Fafard, Characterization of a full-scale prebaked carbon anode using $\mathrm{x}$-ray computerized tomography, Light Metals, (2011), 973-975.

15. D. Picard, H. Alamdari, D. Ziegler, B. Dumas, M. Fafard, Characterization of pre-baked carbon anode samples using x-ray computed tomography and porosity estimation, Light Metals, (2012), 1283-1288.

16. Y. Shintaku, Y. Ohara, M. Hashimoto, S. Horinouchi, K. Yamanaka, Evaluation of stress corrosion cracks in metals by linear and nonlinear ultrasound (proceedings of 20th international congress on Acoustics, ICA ,2010), 1-4.

17. J. L. Sandoz, B. Yann, L. Demay, Wood testing using acousto-ultrasonic. 12th Int. Symposium on Nondestructive Testing of Wood, Sopron, (2000), 97-104.

18. S, Jean-Luc., B. Yann, Evaluation de la qualité des arbres sur pied en utilisant l'analyse acosto-ultrasonique.

19. S. Jean-Luc, B. Yann, Timber grading machine using multivariate parameters based on ultrasonic and density measurement, COST E 53 Conference - Quality Control for Wood and Wood Products, 15th - 17th October (2007), 167-173.

20. H. Saadaoui, Evaluation des endommagements thermiques et mécaniques du composites graphite/epoxyde par emission Acousto-Ultrasonique (Master thesis, Université of Moncton, 1996), 49-54.

21. A. Vary, The Acousto-Ultrasonic Approach, Theory and application, NASA Technical Memorandum, (1987), 8.

22. R. C. Perruchoud, W. K. Fischer, Determination of the sodium sensitivity of petroleum coke, Light Metals (1991), anode for the aluminum industry, (R \& D carbon, 4eme edition, 2007), 39-44.

23. W. K. Fischer, R. C. Perruchoud, Bench scale evaluation of the mechanical and chemical behavior of the coke and anode manufacturing, RDC internal publication (1992), anode for the aluminum industry (R \& D carbon, 4eme edition, 2007), 93-96.

25. U. Mannweiler, Anode manufacturing: an Introduction RDC internal publication (1994), anode for the aluminum industry (R \& D carbon, 4eme edition, 2007), 197-201.

26. W. K. Fischer, R. C. Perruchoud, Pitch evaluation, RDC internal publication, (1992), anode for the aluminum industry (R \& D carbon, 4eme edition, 2007), 141-144.

27. U. Buhler, R. C. Perruchoud, Dynamic process optimization, Light Metals (1995), anode for the aluminum industry (R \& D carbon, 4eme edition, 2007), 227-228.
28. P. Sulzberger, Camalco, Improvements through changes in bake operation and control, (1992), anode for the aluminum industry (R \& D carbon, 4eme edition, 2007), 264-266.

29. W. K. Fischer, F. Keller, R. C. Perruchoud, S. Oderbolz, Baking parameters resulting anode quality, Light Metals (1993), Anode for the aluminum industry (R \& D carbon, ltd, 4eme edition 2007), 267-280.

30. ASTM D5502-00(2005), Standard Test Method for Apparent Density by Physical Measurements of Manufactured Anode and Cathode Carbon Used by the Aluminum Industry, ASTM International (2010), 12251226.

31. ASTM D6120-97(2007), Standard Test Method for Electrical Resistivity of Anode and Cathode Carbon Material at Room Temperature ASTM International (2007), 320-322. 